\author{
Journal of Chemical, Biological and Physical Sciences

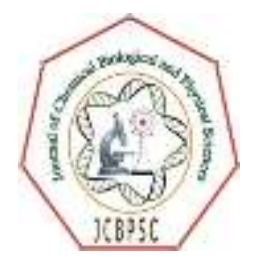 \\ An International Peer Review E-3 Journal of Sciences \\ Available online atwww.jcbsc.org \\ Section A: Chemical Sciences

\title{
A comparative study of corrosion combating capacity of natural occurring plant (Catharanthus roseus) and synthesized Schiff's base on Aluminium in HCl solution.
}

\author{
Anuja Khed"and R.K.Upadhyay \\ *Synthesis and Surface Science Laboratory, Government College, Ajmer, Rajasthan, India.
}

Received: 28June2020; Revised: 11 July 2020; Accepted: 03 August 2020

\begin{abstract}
Leaf extract of Catharanthus roseus and newly synthesized Schiff's base were taken for studying the corrosion combating capacityon Aluminium in $\mathrm{HCl}$ solution. Weight loss and thermometric techniques were used for the studies. For weight loss $0.5 \mathrm{M}, 1 \mathrm{M}, 1.5 \mathrm{M}$ and $2 \mathrm{M}$ and for thermometric analysis, $1 \mathrm{M}, 2 \mathrm{M}$ and $3 \mathrm{M}$ concentrations of $\mathrm{HCl}$ solutions were taken.Inhibitor concentrations were taken $0.1 \%$, $0.3 \%, 0.5 \%$ and $0.7 \%$ in these methods. Results show concurrence mutually and illustrate that the corrosion combating capacity of leaf extract of Catharanthus roseuswas more than newly synthesized Schiff's base. Furthermore, results revealed that corrosion combating capacity increases with the increase in the concentration of the acid as well as those of inhibitors. Maximum efficiency was found to be $99.31 \%$ for $2 \mathrm{M}$ concentration of $\mathrm{HCl}$ at $0.7 \%$ concentration of leaf extracts of the Catharanthus roseus whereas for Schiff's base with similar concentrations it was found to be $77.83 \%$.
\end{abstract}

Keywords: Corrosion, Catharanthusroseus, Schiff's base, Inhibition efficiency, Corrosion Rate, Reaction Number, SEM.

\section{INTRODUCTION}

Corrosion is a process which occurs naturally. Corrosion is a destructive phenomenon which is chemical or electro chemical in nature. ${ }^{1-2}$ It can be understood as the gradual destruction of the metallic surface by the chemical or more precisely electrochemical reaction of the metal with its surroundings. Corrosion not only changes the physical and chemical characteristics of metals and 
alloys but it also decreases strength as well as other features which hinder the metal from its specific uses.

The naturally occurring plant products are environment friendly as well as ecologically acceptable, along with properties like inexpensiveness, easy availability and renewability. A lot of investigations regarding the exploration of corrosion inhibition properties of various plant products like tannins, alkaloids, organic amino acids and organic dyes are being done in the whole world ${ }^{3}$. Some naturally occurring products like Opuntia ${ }^{4}$, $\mathrm{Neem}^{5}$, Trifla ${ }^{6}$, Holy Basil ${ }^{7}$ etc have been studied as corrosion inhibitors. In present study, Catharanthus roseushas been selectedto explore its corrosion combating capacity. This plant is conveniently available in all the seasons. It is commonly known as "Sadabahar" which literally means it blossoms in every season. It is an important medicinal plant containing alkaloids like vinblastine and vincristine that are used to fight cancer ${ }^{8}$.
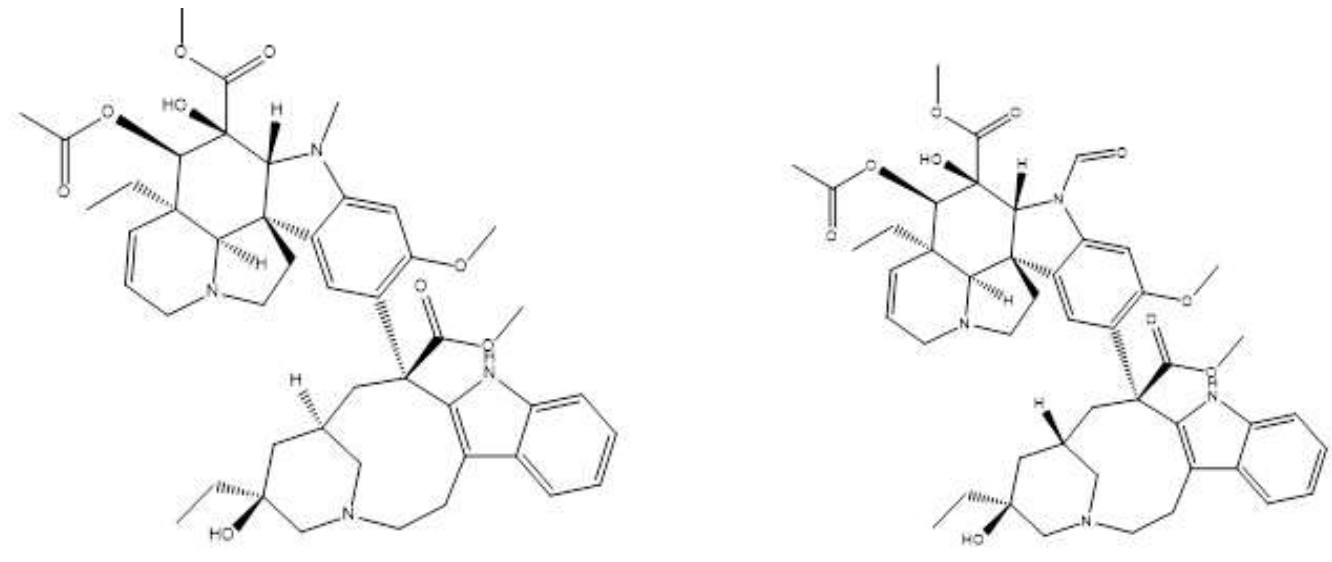

Vinblastine Vincristine

Parallel studies have also been done throughout the globe for the corrosion inhibiting actions of the chemically synthesized compounds like Schiff's bases. ${ }^{9-13}$

In present investigation Aluminum has been selected for corrosion studies as it is a widely used metal in many industries and construction due to its remarkable qualities ${ }^{14-15}$ likehigh conductivity, nontoxicity and recyclability, which are evident from its cosmopolitan uses. After iron, it is ranked second leading used metal. Its malleability and ductility permits it to take various shapes. It can be used under a wide range of temperature. It also shows resistance to corrosion due to its oxide layer, which increases the life span of products made from aluminum. Furthermore, high conductivity, nontoxicity and easy availability are also some major characteristics of aluminum. The role of alloying elements in the control of corrosion and application of film forming inhibitors are well known ${ }^{16}$.In the present investigation the corrosion combating capacity of newly synthesized Schiff's base and extracts of leaves of Catharanthus roseus have been studied for Aluminum in hydrochloric acid solutions.

\section{EXPERIMENTAL}

Square shaped specimens of Aluminum foil having dimension $2.5 \mathrm{~cm} \times 2.5 \mathrm{~cm} \times 0.042 \mathrm{~cm}$ containing a small hole of about $0.02 \mathrm{~cm}$ diameter near the upper edge were taken. The approximate chemical composition of the specimen was $99 \% \mathrm{Al}, 0.5 \% \mathrm{Fe}, 0.3 \% \mathrm{Si}$ and $0.2 \% \mathrm{Cu}$. A single sheet of uniform thickness was used to prepare all the specimens. These specimens were then washed thoroughly using 
acetone and dried by hot air dryer. Then, each and every specimen was weighed up to an accuracy of $0.1 \mathrm{mg}$, with the help of a digital balance.

The acid solutions were prepared by the use of double distilled water. Only analytical reagent grade chemicals were used. Investigations were carried out in $0.5 \mathrm{M}, 1 \mathrm{M}, 1.5 \mathrm{M}$ and $2 \mathrm{M}$ concentrations of $\mathrm{HCl}$ solution.

For the preparation of Schiff's base, conventional method was used i.e. equimolar quantities of napthylamine and 4-methyl benzaldehyde were refluxed. $0.1 \%, 0.3 \% .0 .5 \%$ and $0.7 \%$ inhibitor concentrations were taken in alcohol for the preparation of test solutions. Specimens are suspended with a ' $\mathrm{V}$ ' shaped glass hook and left exposed to air in beaker containing $50 \mathrm{~mL}$ test solution. These test specimens were washed with running water after adequate exposure and then weighed again.

The inhibition efficiency $\eta \%$ was calculated as ${ }^{17}:-$

$$
\eta \%=\frac{\left(\Delta \mathbf{W}_{\mathbf{u}}-\Delta \mathbf{W}_{\mathbf{i}}\right)}{\Delta \mathbf{W}_{\mathbf{u}}} \times 100
$$

Where,

$\mathrm{W}_{\mathrm{u}}$ is the weight loss in uninhibited solution and

$\mathrm{W}_{\mathrm{i}}$ is the weight loss in inhibited solution

Corrosion rate $\left(\frac{m m}{y r}\right)$ can be calculated by following formula ${ }^{18}:-$

$$
\text { Corrosion Rate }\left(\frac{\mathrm{mm}}{\mathrm{yr}}\right)=\frac{87.6 \Delta \mathrm{W}}{\mathrm{DAT}}
$$

Where, $\Delta \mathrm{W}$ is weight loss in $\mathrm{mg}, \mathrm{D}$ is the metal density in $\mathrm{g} \cdot \mathrm{cm}^{-3}, \mathrm{~A}$ is the exposed area in $\mathrm{cm}^{2}, \mathrm{~T}$ is the time of exposure in hours .

Inhibition efficiencies were also found by one more technique, viz thermometric method. In this method, single specimen, of dimensions same as were used in weight loss method was immersed in a thermally insulated reaction chamber containing $50 \mathrm{~mL}$ of test solution at an initial temperature (Ti). Temperature variations were monitored at regular intervals of time using a thermometer with an accuracy of $0.1{ }^{\circ} \mathrm{C}$. The increase in temperature was slow in the beginning and then speedy and finally attained to maximum $(\mathrm{Tm})$ and then begun to decrease. The percentage inhibition efficiency $\eta \%$ was calculated as ${ }^{19}:-$

$$
\boldsymbol{\eta} \%=\frac{\left(\mathbf{R N}_{\mathbf{u}}-\mathbf{R N}_{\mathbf{i}}\right)}{\mathbf{R N}_{\mathbf{u}}} \times \mathbf{1 0 0}
$$

Where,

$\mathrm{RN}_{\mathrm{u}}$ is the reaction number in uninhibited solution,

$\mathrm{RN}_{\mathrm{i}}$ is the reaction number in inhibited solution

Reaction Number $(\mathrm{RN})$ can be calculated in terms of temperature as ${ }^{20}$ :-

$$
\text { Reaction Number }(R N)=\frac{\left(T_{m}-T_{i}\right)}{t}
$$

Where, 
$\mathrm{T}_{\mathrm{m}}$ is the maximum temperature of the test solution,

$\mathrm{T}_{\mathrm{i}}$ is the initial temperature of the test solution and

$\mathrm{t}$ is the time in minutes to attain maximum temperature

\section{RESULT AND DISCUSSION}

Weight loss and percentage inhibition efficiencies $(\eta \%)$ for different concentrations of $\mathrm{HCl}$ and inhibitors are shown in table 1. It is observed that percentage inhibition efficiency increases with the increase in the concentrations of the acid and also with the increase in the concentrations of inhibitors. Both the inhibitors show maximum inhibition efficiency at higher concentration of acid i.e. at $2 \mathrm{M}$ at their highest concentration i.e. at $0.7 \%$.The maximum efficiency was shown by Catharanthus roseus is $(99.31 \%)$ corresponding corrosion rate $(\mathrm{mm} / \mathrm{yr})$ is also shown in table $\mathbf{1}$. It is observed that corrosion rate of aluminium decreases with the increase in the concentrations of inhibitors whereas corrosion rate increases with the increase in the strength of $\mathrm{HCl}$ solutions. Inhibition efficiencies determined by thermometric method are shown in table 2 .

Since no significant changes in temperature were recorded for lower concentrations of acid so observations were taken at higher concentrations i.e. $2 \mathrm{M}$ and $3 \mathrm{M}$ along with lower concentration i.e. $1 \mathrm{M}$. The results shown by thermometric method have the same trends as were observed in weight loss method. In thermometric method also the inhibition efficiency increases with the increase in the concentrations of both acid and inhibitors. Here also the best result is shown by leaves extract of Catharanthus roseus. The maximum efficiency is $88.00 \%$ in $3 \mathrm{M}$ HClat $0.7 \%$ concentration. It means both methods have good agreement with each other. The variation of Reaction number (RN) with inhibitor concentration shows that the reaction number decreases with increasing concentration of inhibitors. Both the methods show that the naturally occurring plant is more efficient than chemically synthesized compound. It may be due to the fact that in the naturally occurring plant may have more hetero atoms than chemically synthesized compound. The mechanism of corrosion inhibition by natural plant is very complicated but it may be supposed that it is basically based upon the phenomenon of chemisorption.

It is supposed that alkaloids present in the extract of leaves of Catharanthus roseus are basic in nature; they are adsorbed on the surface of metal in presence of acid and thus block the active sites on the surface, which are responsible for the corrosion of metal. More the adsorption more will be the efficiency of the inhibitor and more the concentration of inhibitor more will be its adsorption on the surface of metal reducing exposed sites of metal for attack on metal. The inhibition efficiency also increases with increasing concentration of acid which is due to the fact that inhibitor is basic in nature which is more dissociated in more acidic conditions and thus get more adsorbed on the surface of metal. The leaves extract of Catharanthus roseus plant is more efficient than the chemically synthesized Schiff's base. It may be due to the presence of more hetero atoms in the leaves extract of Catharanthus roseus plant, which are the centers of more electron density which covers the active sites of metal.

In the SEM method pure specimen of Aluminum, specimen after exposure in $2 \mathrm{M} \mathrm{HCl}$, specimen after exposure in $2 \mathrm{M} \mathrm{HCl}$ in presence of Catharanthus roseus at the concentration of $0.7 \%$ and specimen after exposure in $2 \mathrm{M} \mathrm{HCl}$ in presence of Schiff base at the concentration of $0.7 \%$ were analysed and the difference in the change of their surface structures were observed.

Scanning electron microscope (SEM) analysis of Aluminum sample have been performed by MNIT, Jaipur with mag $=1000 \mathrm{X}$. 
Table 1: Weight Loss $(\Delta \mathrm{w})$, Inhibition Efficiency $(\eta \%)$ and Corrosion Rate data for Aluminium in HCl Solution with given InhibitorsArea of specimen: $6.25 \mathrm{~cm}^{2}$

\begin{tabular}{|c|c|c|c|c|c|c|c|c|c|c|c|c|}
\hline \multirow{3}{*}{$\begin{array}{c}\text { Conc. Of } \\
\text { inhibitor \% }\end{array}$} & \multicolumn{3}{|c|}{$0.5 \mathrm{M} \mathrm{HCl}$} & \multicolumn{3}{|c|}{$1 \mathrm{M} \mathrm{HCl}$} & \multicolumn{3}{|c|}{$1.5 \mathrm{M} \mathrm{HCl}$} & \multicolumn{3}{|c|}{$2 \mathrm{M} \mathrm{HCl}$} \\
\hline & \multicolumn{3}{|c|}{ (48 Hours ) } & \multicolumn{3}{|c|}{ (8 Hours 15 mins ) } & \multicolumn{3}{|c|}{ (1 Hour 10 mins ) } & \multicolumn{3}{|c|}{ (30 mins ) } \\
\hline & $\begin{array}{c}\Delta \mathrm{w} \\
(\mathrm{mg})\end{array}$ & $\begin{array}{l}\text { Inhibition } \\
\text { Efficiency } \\
(\boldsymbol{\eta} \%)\end{array}$ & $\begin{array}{l}\text { Corrosion } \\
\text { Rate } \\
(\mathrm{mm} / \mathrm{yr})\end{array}$ & $\begin{array}{l}\Delta \mathrm{W} \\
(\mathrm{mg})\end{array}$ & $\begin{array}{l}\text { Inhibition } \\
\text { Efficiency } \\
(\boldsymbol{\eta} \%)\end{array}$ & $\begin{array}{l}\text { Corrosion } \\
\text { Rate } \\
(\mathrm{mm} / \mathrm{yr})\end{array}$ & $\Delta \mathrm{w}(\mathrm{mg})$ & $\begin{array}{l}\text { Inhibition } \\
\text { Efficiency } \\
(\boldsymbol{\eta} \%)\end{array}$ & $\begin{array}{l}\text { Corrosion } \\
\text { Rate } \\
(\mathrm{mm} / \mathrm{yr})\end{array}$ & $\Delta \mathrm{w}(\mathrm{mg})$ & $\begin{array}{l}\text { Inhibition } \\
\text { Efficiency } \\
(\mathbf{\eta} \%)\end{array}$ & $\begin{array}{l}\text { Corrosion } \\
\text { Rate } \\
(\mathrm{mm} / \mathrm{yr})\end{array}$ \\
\hline Uninhibited & 234.7 & & 26.57 & 305.0 & & 200.86 & 350.2 & & 1640.20 & 362.6 & & 3940.00 \\
\hline \multicolumn{13}{|c|}{ Catharanthusroseus } \\
\hline 0.1 & 90.2 & 61.57 & 10.21 & 90.0 & 70.49 & 59.27 & 22.0 & 93.72 & 103.04 & 8.3 & 97.71 & 90.19 \\
\hline 0.3 & 64.0 & 72.73 & 7.24 & 74.4 & 75.61 & 49.00 & 17.5 & 95.00 & 81.96 & 5.4 & 98.51 & 58.68 \\
\hline 0.5 & 52.3 & 77.72 & 5.92 & 60.0 & 80.33 & 39.51 & 14.3 & 95.92 & 66.98 & 3.5 & 99.03 & 38.03 \\
\hline 0.7 & 49.4 & 78.95 & 5.59 & 58.2 & 80.92 & 38.33 & 12.0 & 96.57 & 56.20 & 2.5 & 99.31 & 27.16 \\
\hline \multicolumn{13}{|c|}{ Schiff's base } \\
\hline 0.1 & 160.0 & 31.83 & 18.11 & 200.00 & 34.43 & 131.71 & 177.00 & 49.46 & 829.00 & 170.00 & 53.12 & 1847.21 \\
\hline 0.3 & 125.1 & 46.70 & 14.16 & 150.2 & 50.75 & 98.91 & 150.00 & 57.17 & 702.54 & 117.30 & 67.65 & 1274.58 \\
\hline 0.5 & 102.3 & 56.41 & 11.58 & 115.00 & 62.30 & 75.73 & 120.00 & 65.73 & 562.03 & 100.00 & 72.42 & 1086.60 \\
\hline 0.7 & 80.0 & 65.91 & 9.05 & 100.20 & 67.15 & 65.99 & 85.30 & 75.64 & 399.51 & 80.40 & 77.83 & 873.62 \\
\hline
\end{tabular}


Table 2: Reaction Number (RN )and Inhibition Efficiency ( $\eta \%)$ data for $\mathrm{Al}$ in $\mathrm{HCl}$ Solution with given Inhibitors

Temperature :- $303 \pm 0.1 \mathrm{~K}$

Area of specimen :- $6.25 \mathrm{~cm}^{2}$

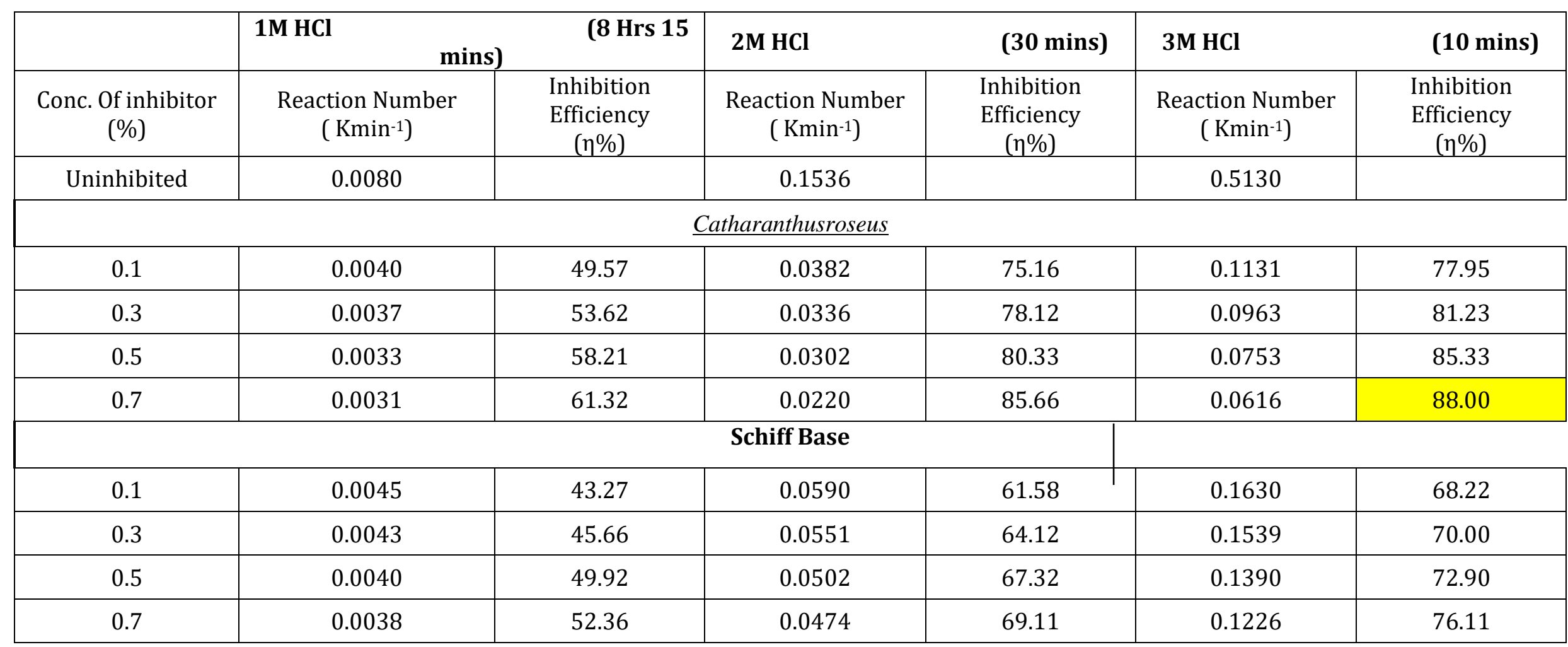




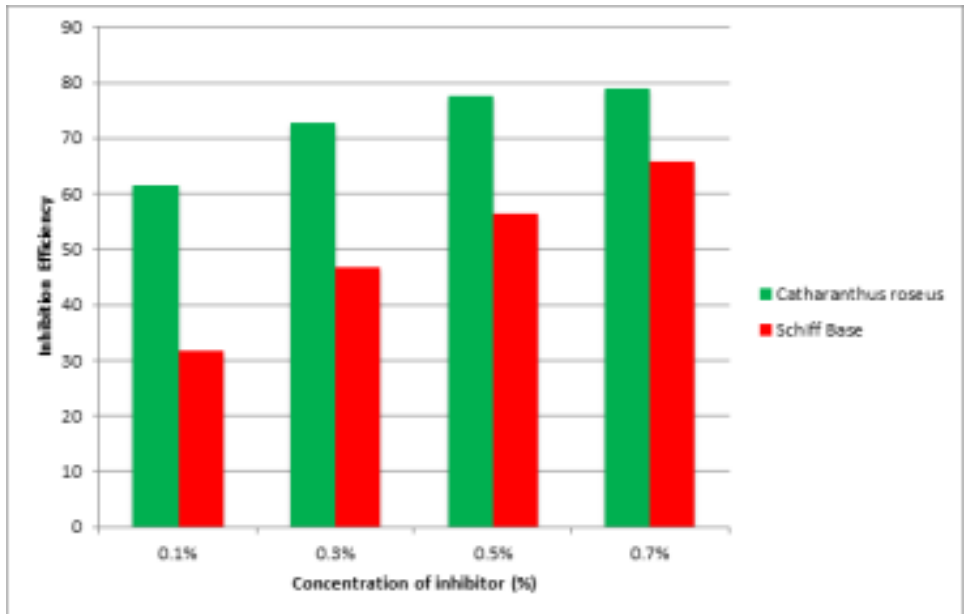

Fig. 1: Variation of inhibition efficiency with concentration of inhibitor on Aluminium in $0.5 \mathrm{M} \mathrm{HCl}$

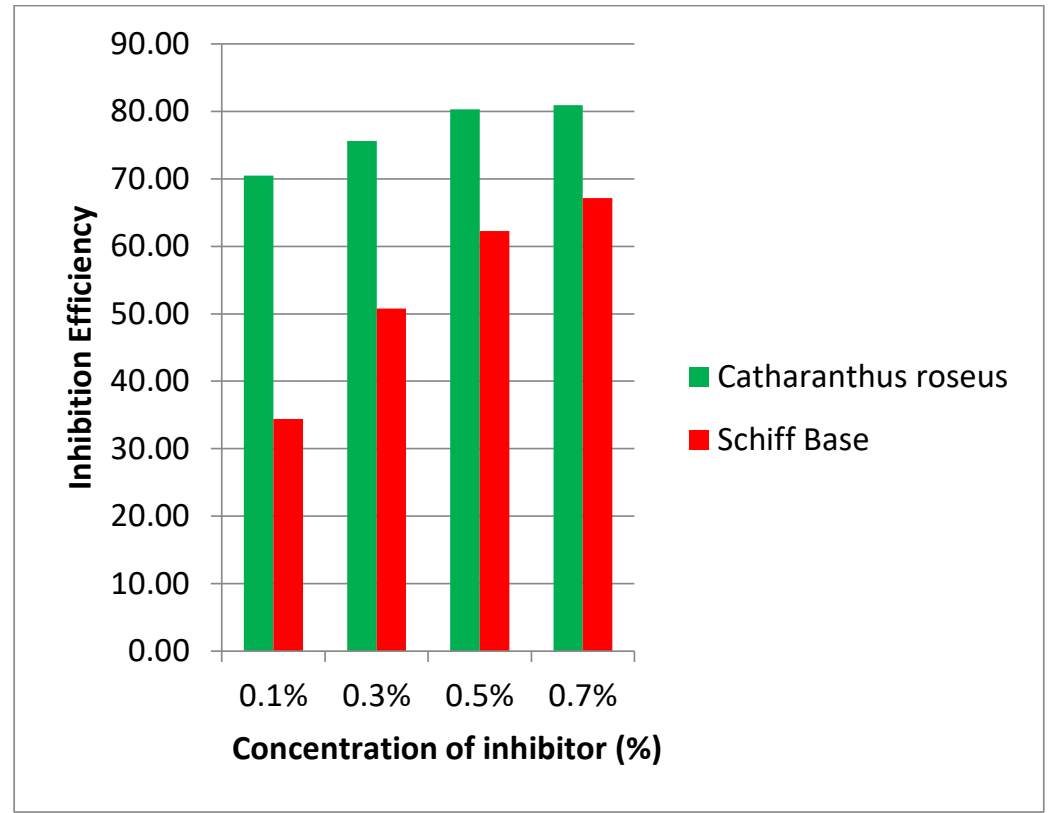

Fig. 2: Variation of inhibition efficiency with concentration of inhibitor on Aluminium in $1 \mathrm{M} \mathrm{HCl}$

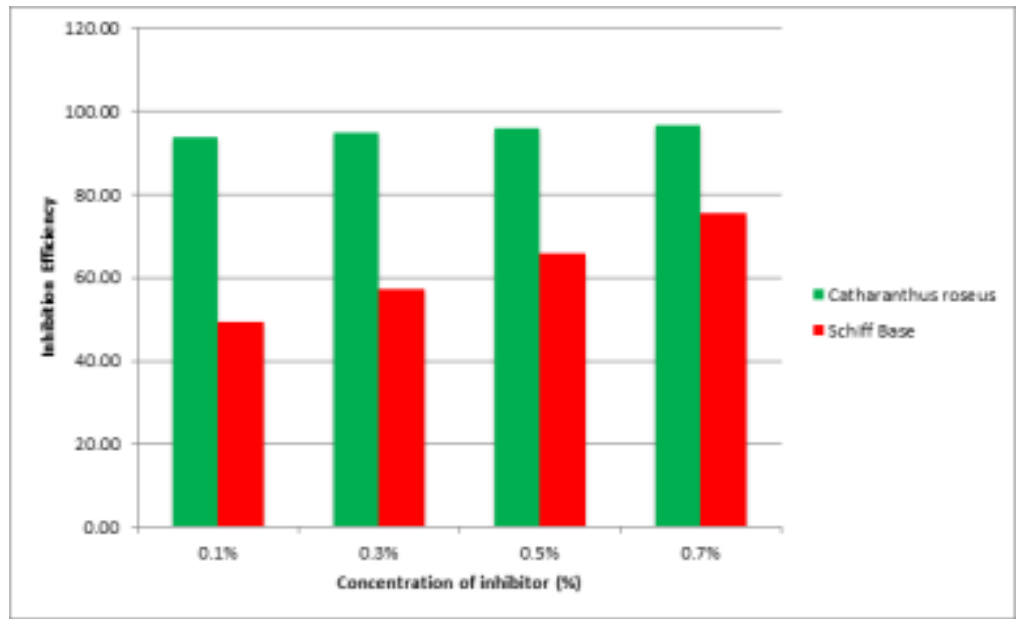

Fig. 3: Variation of inhibition efficiency with concentration of inhibitor on Aluminium in $1.5 \mathrm{M} \mathrm{HCl}$

392 J. Chem. Bia. Phy. Sci. Sec. A, August 2020 -Qctaber 2020, Val. 10, №. 4; 38g-396. DOI:10.24214/jcbps.A.10.4.38696.] 


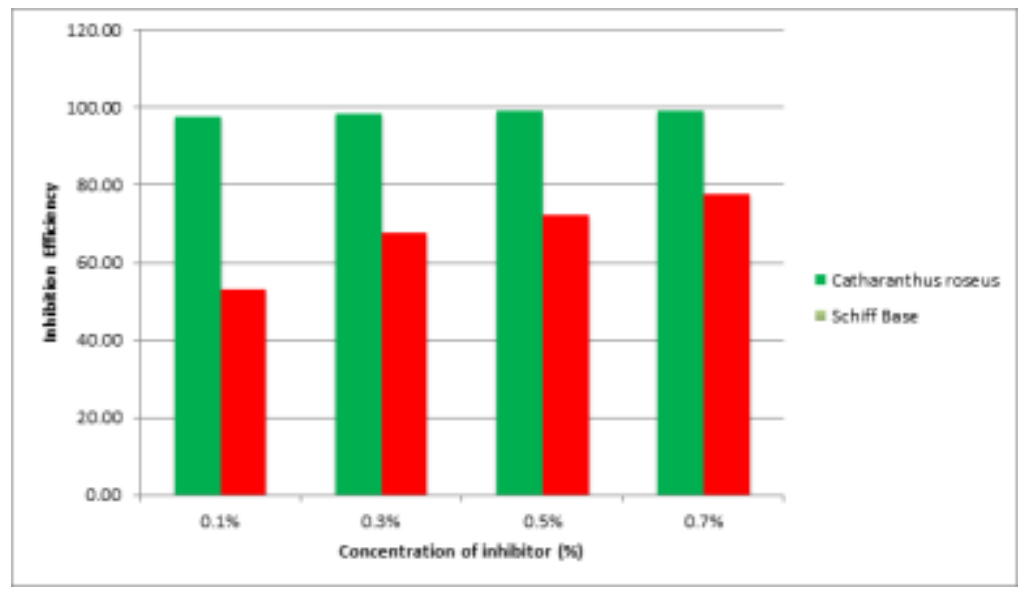

Fig. 4: Variation of inhibition efficiency with concentration of inhibitor on Aluminium in $2 \mathrm{M} \mathrm{HCl}$

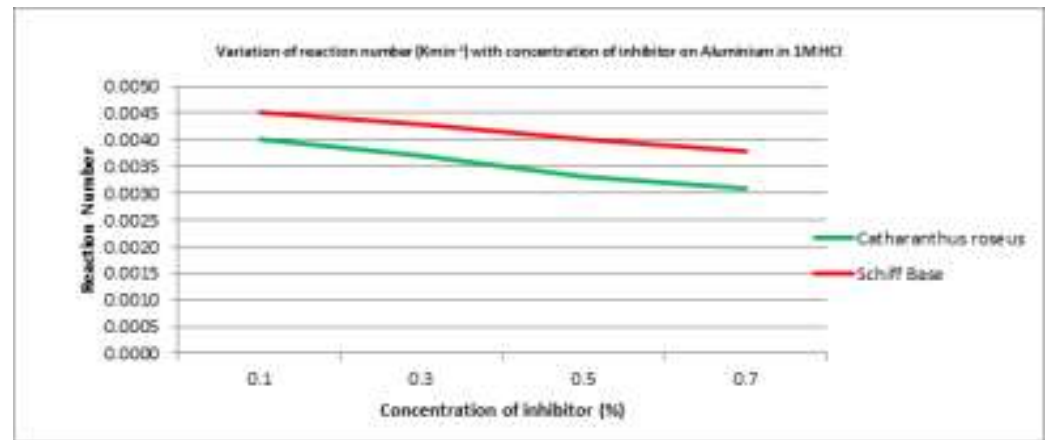

Fig.5: Variation of reaction number $\left(\mathrm{Kmin}^{-1}\right)$ with concentration of inhibitor on Aluminium in $1 \mathrm{M} \mathrm{HCl}$

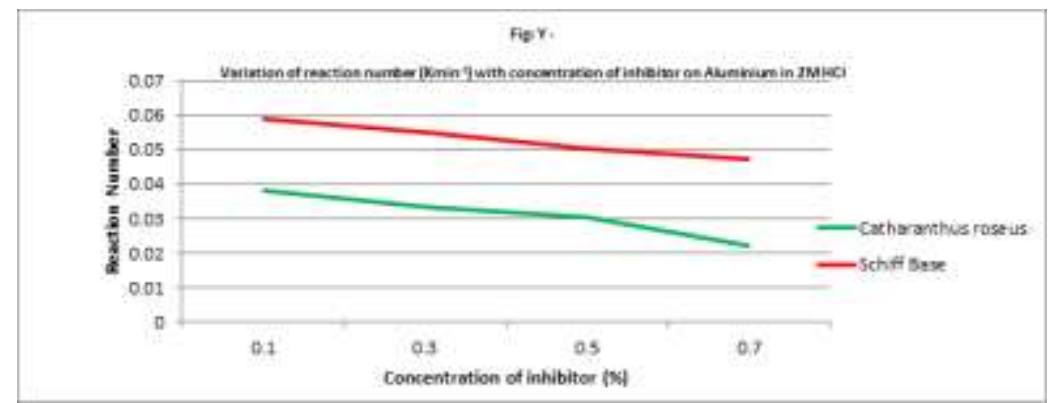

Fig.6: Variation of reaction number $\left(\mathrm{Kmin}^{-1}\right)$ with concentration of inhibitor on Aluminium in $2 \mathrm{M} \mathrm{HCl}$ 


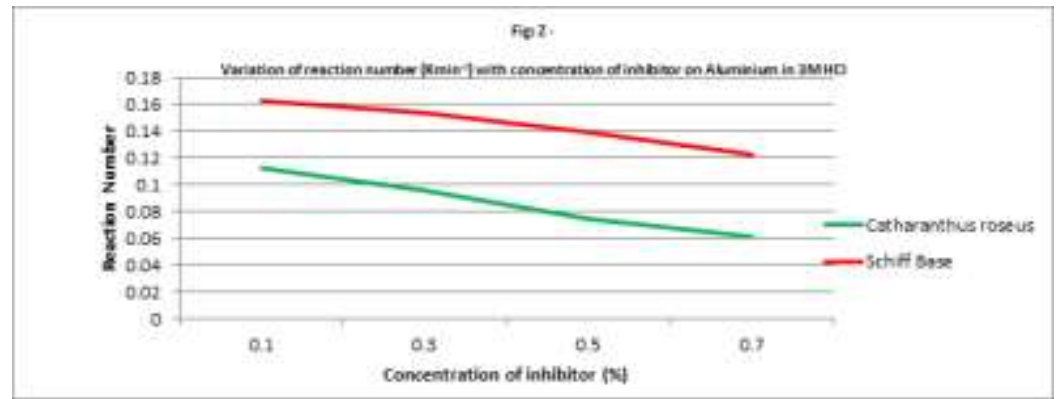

Fig.7: Variation of reaction number $\left(\mathrm{Kmin}^{-1}\right)$ with concentration of inhibitor on Aluminium in $3 \mathrm{M}$ $\mathrm{HCl}$

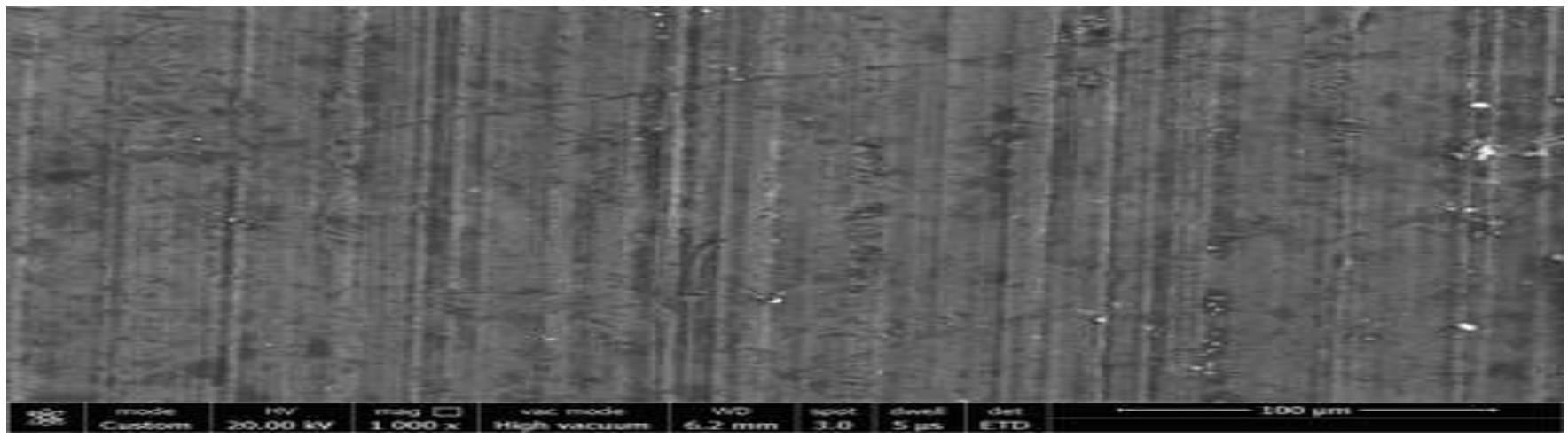

Fig.8: SEM for pure Aluminium

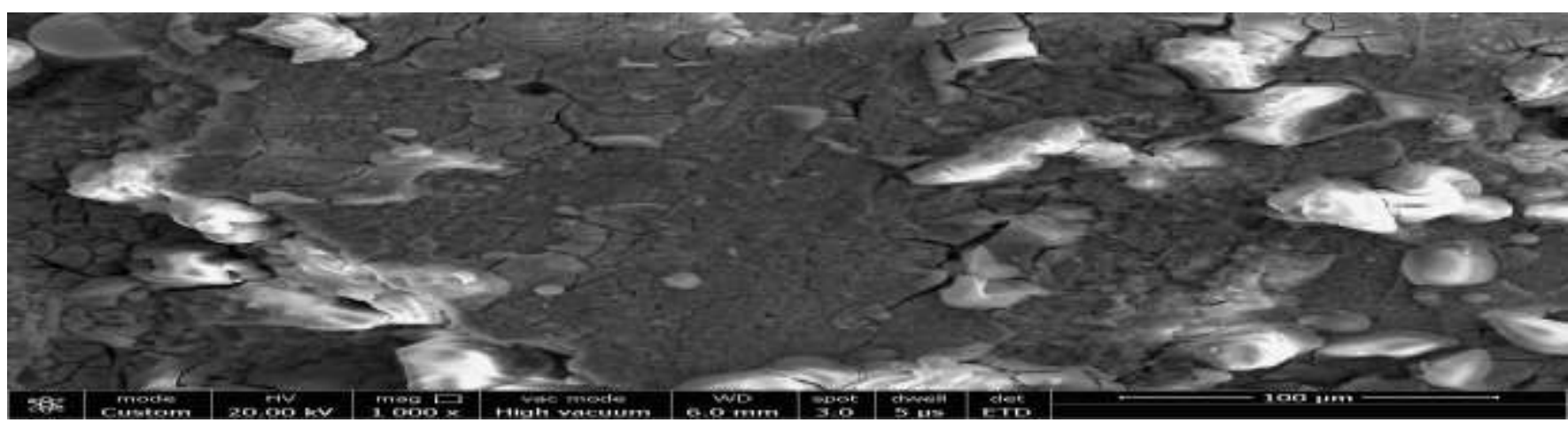

Fig.9: SEM for Aluminium in $2 \mathrm{M} \mathrm{HCl}$

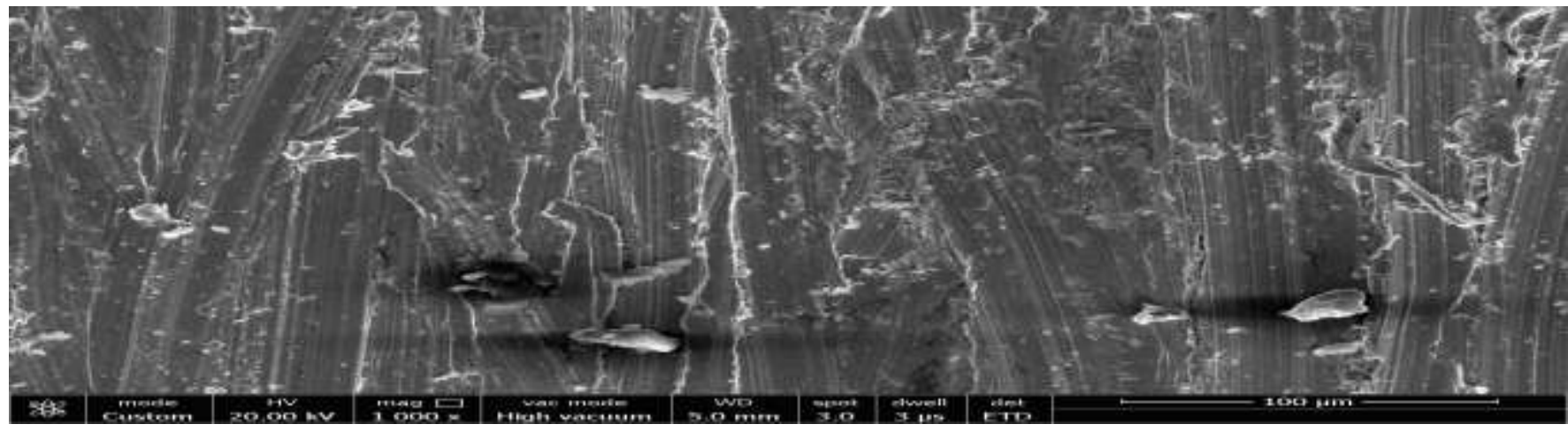

Fig.10: SEM for Aluminium in $2 \mathrm{M} \mathrm{HCl}$ with inhibitor Catharanthusroseus $(0.7 \%)$ 


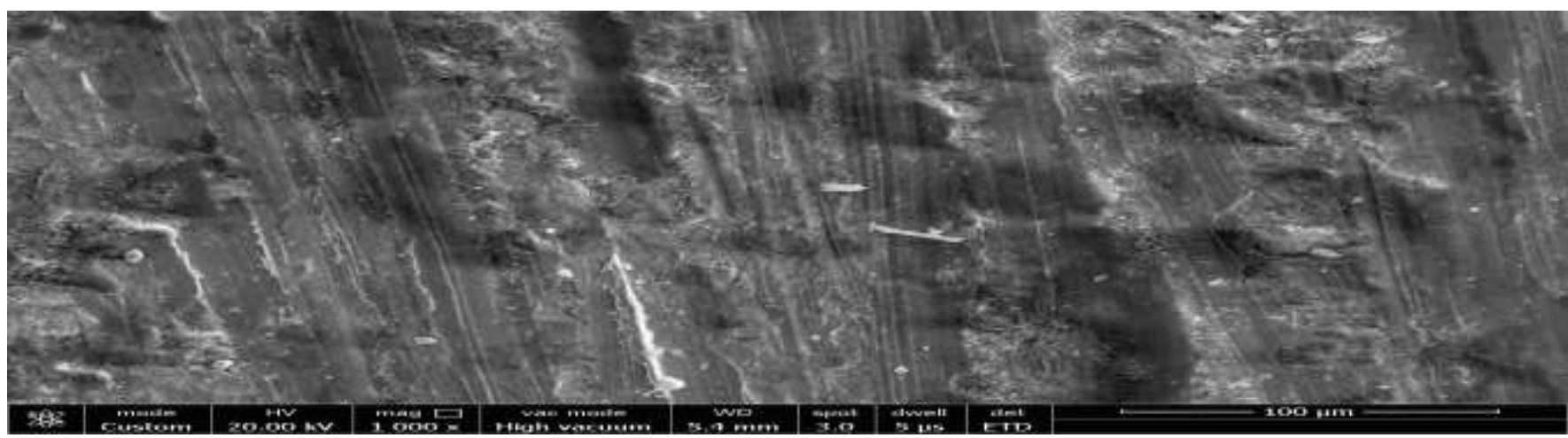

Fig.11: SEM for Aluminium in 2M HCl with inhibitor Schiff Base $(0.7 \%)$

\section{CONCLUSIONS}

From the above studies it can be concluded that although both Catharanthusroseus as well as synthesized Schiff's base act as corrosion combating agents for aluminium in $\mathrm{HCl}$ acid but Catharanthusroseus extract is found to be more efficient than the chemically synthesized one.

\section{ACKNOWLEDGEMENTS}

The authors are highly thankful to the Materials Research Centre, MNIT, Jaipur, for the surface analysis of the samples using SEM technology through the Nova Nano FE-SEM 450 (FEI) instrument.

\section{REFERENCES}

1. Anonymous, Bull. Amer, Zinc inst., 11, 82, (1928).

2. W.R. Whitney, J. Amer, Chem. Soc.25, 394, (1903).

3. B. E. Amitha Rani and Bharathi Bai J. Basu, International Journal of Corrosion, Article ID 380217, (2012).

4. A. Y. El-Etre, " Inhibition of aluminium corrosion using Opuntia extract," Corrosion Science, vol.45, no. 11, 2485, (2003).

5. U. J. Ekpe, E. E. Ebenso, and U. J. Ibok, "Inhibitory action of Azadirachta indica leaves extract on the corrosion of mild steel in $\mathrm{H}_{2} \mathrm{SO}_{4}$," West African Journal of Biological and Applied Chemistry,37,13, (1994).

6. M. J. Shangvi, S. K. Shukla, A. N. Mishra, M. R. padh, and G. N. Mehta, "Corrosion inhibition of mild steel in hydrochloric acid by acid extracts of Sapindus Trifolianus, Acacia Concian and Trifla,"Transactions of the Metal Finishers Association of India,5(3),143, (1996).

7. N.Kumpawat, A.Chaturvedi, R. K. Upadhyay. J Protection of Metals and Physical Chemistry of Surfaces. 46(2)267,(2010).

8. Ajaib M, Khan Zud, Khan N, Wahab M, Ethnobotanical studies on useful shrubs of District Kotli, Azad Jammu \& Kashmir, Pakistan, Pak J Bot.,42, 1407-1415, (2010).

9. Pooja Sharma, R. K. Upadhyay,et. al. JTR Chem15(1)21, (2008). 
10. N.Kumpawat, A.Chaturvedi, R. K. Upadhyay. J Protection of Metals and Physical Chemistry of Surfaces.46(2)267,(2010).

11. A. Bansiwal, P. Anthony and S.P. Mathur, Br. Corros.J.35, 301,(2000).

12. R. K. Upadhyay and S.P. Mathur, J. Electrochem.Soc.Ind.2, 55, (2006).

13. R. K. Upadhyay and S.P. Mathur, E-Journal of Chem.3, 4,(2007).

14. M.P. Mudlec, A.W. Thompson and I.M. Benstein, Corros, 57, 268, (1981).

15. "The properties of Aluminium and its alloys" 6thEdition, The Aluminium Federation, Birmingham, (1965).

16. J. Vishal Anand, T. S. Prasana Kumar, D. Mukharji, Study of Corrosion Inhibitors, IJESRT, Bull. Electrochem., 15, 148, (1999).

17. J.D.Talati and D.K.Gandhi,Ind.J.Tech, 29,277,(1997).

18. M.G.Fontana,Corrosion Engineering, $3^{\text {rd }}$ edition, McGraw Hill Book Company, 173,(1987).

19. K.Aziz and A.M. Shams E1-Din, Corrosion. Sci., 5, 489,(1995).

20. F.Mylius,Z.Metalik, 14,239,(1992).

\section{Corresponding author: Anuja Khed,}

*Synthesis and Surface Science Laboratory, Government College, Ajmer, Rajasthan, India

Online publication Date: 03.08.2020 